\section{OPEN ACCESS}

Edited by:

Sónia P. Gonçalves,

University of Lisbon, Portugal

Reviewed by:

Inmaculada Méndez,

University of Murcia, Spain

Azita Fathnezhad-Kazemi,

Islamic Azad University of Tabriz, Iran

*Correspondence:

Ana Belén Barragán Martín abm410@ual.es

Specialty section

This article was submitted to Health Psychology,

a section of the journal

Frontiers in Psychology

Received: 17 March 2021

Accepted: 27 July 2021

Published: 03 September 2021

Citation:

Martos Martínez Á, Molero Jurado MdM, Pérez-Fuentes MdC,

Barragán Martín AB, Simón

Márquez MdM and Gázquez Linares JJ (2021) Role of Personality and Positive and Negative Affects in

Coping Strategies of Nurses: A

Cross-Sectional Study.

Front. Psychol. 12:682153.

doi: 10.3389/fpsyg.2021.682153

\title{
Role of Personality and Positive and Negative Affects in Coping Strategies of Nurses: A Cross-Sectional Study
}

\author{
África Martos Martínez ${ }^{1}$, María del Mar Molero Jurado ${ }^{1}$, \\ María del Carmen Pérez-Fuentes ${ }^{1,2}$, Ana Belén Barragán Martín ${ }^{1 *}$, \\ María del Mar Simón Márquez ${ }^{1}$ and José Jesús Gázquez Linares ${ }^{3}$
}

${ }^{1}$ Department of Psychology, Faculty of Psychology, University of Almería, Almería, Spain, ${ }^{2}$ Department of Psychology, Universidad Politécnica y Artística del Paraguay, Asunción, Paraguay, ${ }^{3}$ Department of Psychology, Universidad Autónoma de Chile, Providencia, Chile

Nurses are exposed to many highly stressful events. Individual variables, such as personality and affective state, have been related to vulnerability to maladaptive coping. Therefore, the objectives of this study were to analyze the relationships between the personality, positive and negative affects, and coping strategies of nurses and to establish the mediating role of affective state in the relationship between personality and coping. The sample was made up of 1,268 Spanish nurses aged 22-63 years who completed the Coping Strategies Inventory, the Positive and Negative Affect Schedule, and the 10-item Big Five Inventory. Descriptive analyses, correlations, and mediation models were estimated. The results showed relationships between the Big Five personality factors, positive and negative affects, and coping strategies. Negative affect was confirmed as a mediator between personality and less adaptive strategies and positive affect was confirmed on positive strategies. This study emphasizes the need to develop actions directed at teaching nurses adequate problem-solving strategies and training them in the ability to assign a different emotional value to complex situations.

Keywords: personality, affect, coping strategies, nurses, descriptive of survey study

\section{INTRODUCTION}

In spite of the importance of wellbeing of healthcare professionals in ensuring quality care and patient safety (Hall et al., 2016), this group is habitually exposed to highly stressful situations (Pérez-Fuentes et al., 2019a; Tirado et al., 2019; Wijn and van der Doef, 2020). This generates special vulnerability in nurses to develop burnout (Molero et al., 2018a,b), depression, and negative moods (Schürmann and Magraf, 2018; Veiga et al., 2019).

\section{Coping Strategies in Nursing}

Coping refers to cognitive and behavioral responses of an individual in confronting and managing stressful situations (Folkman, 2013). Not all forms of coping are considered beneficial. Adopting strategies, such as self-blame, or problem avoidance as a way of struggling with stressors lead to maladaptive results (Mark and Smith, 2012; Morales, 2020). Thus, coping responses may be divided into positive and negative. Positive coping refers to direct rational problem-solving, while negative coping refers to avoiding, withdrawing, or denying the problem (Jia et al., 2004). The professionals who use dysfunctional coping strategies show more emotional exhaustion and anxiety, which in 
turn can lead to severe consequences, such as substance abuse, negligence, or changing profession (Bamonti et al., 2019). Similarly, Voskou et al. (2020) showed that nurses who use strategies related to imagining and wishing for alternative scenarios or for escape and problem avoidance have a worse quality of life due to deterioration of their physical and mental health. In this regard, in addition to poor general health, passive coping has also been related to low control and scant job support (Schreuder et al., 2012).

While strategies, such as self-criticism, social withdrawal, and problem avoidance, generate a risk for moral disconnection in the nursing practice, the development of successful strategies enables nurses to advance in their professional labor (Forozeiya et al., 2019). Positive coping skills, such as the use of problem-focused strategies, are related to high standards in resolving complicated situations, better capacity for recovery and resilience, and a healthier work environment (Schreuder et al., 2012; Teismann et al., 2018; Yu et al., 2019). Likewise, employing a positive focus in solving problems and seeking social and emotional support are related to better physical and psychological health of nurses (Voskou et al., 2020).

\section{Personality and Affect in Nursing}

Along with the strategies deployed for facing stressful situations, there are other individual characteristics that affect the job performance and quality of life, such as personality and affective state, of a professional (Barr, 2018). Personality particularly influences a variety of important results in different areas of life of a person, among which is work (Serrano-Fernández et al., 2019). In this line, following the Big Five model, three personality profiles were found in nurses: one group with high scores in extraversion traits, agreeableness, openness to experience and conscientiousness, and low in neuroticism; a second group with high scores in conscientiousness, openness to experience, and neuroticism, but low in agreeableness and extraversion; and a third group with very high scores in neuroticism and low in the rest of the variables. The two last profiles, but especially the one marked by high neuroticism, have been associated with stronger affects by stressful work situations, resulting in a higher prevalence of burnout (Pérez-Fuentes et al., 2019b).

Following Davis and Panksepp (2011), personality and affective states are closely related, and to know the human personality, affective forces and emotional impulses must be understood. With regard to personality and its link with affect, neuroticism has been associated with negative affective state, while conscientiousness, agreeableness, openness, and, especially, extraversion have been linked with positive affect (Hengartner et al., 2017).

\section{Coping Strategies and Personality: Mediation of Positive and Negative Affects}

According to Sahler and Carr (2009), personality characteristics, along with attributional style, form the coping style of an individual. Specifically, the relationship between personality and certain coping styles is due to the personality being able to moderate physiological excitation caused by stress, altering evaluation of the situation, and, therefore, the choice and effectiveness of coping (Wiebe et al., 2018). It, therefore, seems evident that personality traits influence coping (Anisman et al., 2018). So, for example, highly conscientious people tend to use proactive, problem-focused strategies (Straud et al., 2015), and at the same time, they usually feel less anxious and more positive affect than individuals with lower scores in this trait (Korotkov, 2008). Moreover, professionals with a personality marked by neuroticism may try to solve everyday problems with emotional strategies because of their high emotional reactiveness, instead of choosing more effective strategies, such as those focused on the problem (Fornés-Vives et al., 2019). Individuals with high levels of this trait choose more or less regulating responses depending on the affective burden of the situation (Augustine and Larsen, 2011).

Interaction between coping strategies and affect must therefore be considered to understand the regulation dynamics in addition to individual personality differences (Pavani et al., 2017; De la Barrera et al., 2019). It seems that people who feel negative affect at a certain time focus on negative stimuli and restrict their behavior to meditation on past or future problems to overestimate and then avoid the risk, which, in turn, can generate new negative affective experiences (Teismann et al., 2019). Along this line, a negative coping style avoiding the problem has been related to negative affect, while a problem-focused coping is related to positive affect (Dunkley et al., 2017). But further, within this relationship between affect and regulation strategies, personality has a very relevant role. Extraversion and neuroticism are the specific personality traits most involved. Extraversion provokes an initially positive affect in a stressful situation, which, in turn, leads to adaptive coping, while those more neurotic tend to experience negative affect more intensely, which involves the use of rumination and avoidance strategies (Pavani et al., 2017).

As research should concentrate on optimizing the performance and wellbeing of nurses (Dykstra et al., 2016), and nurses must frequently face stressful situations, coping is an important health process which must be included in this collective study (Kellog et al., 2018). Even though personality is relatively stable, coping strategies may be modeled (Wechler et al., 2018). The acquisition and development of effective coping strategies could therefore alleviate anxiety and increase the wellbeing of healthcare professionals (Huang et al., 2018; Molero et al., 2019). Thus, the objective of this study was to analyze the relationships between Big Five personality characteristics, affect (positive and negative), and coping strategies in a sample of nurses and to find out the mediator role of affect in the relationship between personality and coping strategies. The main hypothesis was that positive affect mediates the relationship between personality and more adaptive coping strategies, while, on the contrary, the negative affect mediates the relationship between personality and dysfunctional coping strategies.

\section{METHOD}

\section{Participants}

The original sample was made up of a total of 1,383 nurses in Andalusia (Spain). Those who were unemployed at the time of data collection were excluded $(-68)$. Then, random 
or incongruent answers detected by control questions (CQ) were discarded. After filtering, the final sample was therefore comprised of 1,268 nurses. The mean participant age was 32.02 $(S D=6.91)$ in a range of $22-63$ years. The sex distribution of the sample was $85.3 \%(n=1,081)$ women and $14.7 \%(n=187)$ men, with a mean age of $32.24(S D=6.68)$ and $32.79(S D=$ 6.27 ), respectively.

\section{Instruments}

The sociodemographic characteristics were evaluated with an ad hoc questionnaire including items on participant gender, marital status, and age.

How stressful events are coped with was evaluated using the Inventario de Estrategias de Afrontamiento [Coping Strategies Inventory] (CSI; Cano-García et al., 2007). This instrument consists of 40 items with a five-point Likert-type response scale. It has eight subscales grouped in two secondary scales: adequate management (e.g., I fought to solve the problem), well-focused on the problem (Problem-Solving and Cognitive Restructuring subscales) and well-concentrated on the emotion (Social Support and Emotion Expression subscales); and inadequate management (e.g., I blamed myself), problem focused (Problem Avoidance and Wishful Thinking) and emotion focused (Social Withdrawal and Self-Criticism subscales). The reliability indices were: $\omega=0.883$, the greatest lower bound $(\mathrm{GLB})=0.869$ in problem-solving; $\omega=0.866, \mathrm{GLB}=0.866$ in self-criticism; $\omega=0.823, \mathrm{GLB}=$ 0.843 in emotion expression; $\omega=0.869, \mathrm{GLB}=0.881$ for wishful thinking; $\omega=0.904$, GLB $=0.930$ for social support; $\omega=0.818$, $\mathrm{GLB}=0.828$ for the cognitive restructuring subscale; $\omega=0.749$, $\mathrm{GLB}=0.787$ on problem avoidance; and $\omega=0.784, \mathrm{GLB}=0.824$ for social withdrawal.

The Spanish version (Joiner et al., 1997) of the Positive and Negative Affect Schedule (PANAS Scale; Watson et al., 1988) was used for evaluating the positive and negative affects. This test is comprised of 20 items organized into two groups, 10 on positive affect (e.g., Interested in things) and 10 on negative affect (e.g., Aggressive). The answers are rated on a Likert-type scale in a range of $1-5$ points. Reliability was $\omega=0.753$, GLB $=0.798$ for positive affect and $\omega=0.736, \mathrm{GLB}=0.822$ for negative affect.

The 10-item Big Five Inventory (BFI-10; Rammstedt and John, 2007) was used to evaluate the personality traits. This provides information on the Big Five personality factors (extraversion, conscientiousness, agreeableness, neuroticism, and openness) (e.g., I look like someone who is reserved). Findings support the factorial validity, construct validity, and criterion validity of the BFI-10 (Rammstedt and John, 2007; Rammstedt et al., 2014).

\section{Procedure}

The sample for this cross-sectional study was found by snowball sampling, by publishing it on social networks and texting. A computer-aided web interviewing (CAWI) survey was used to collect the data.

Before data were collected, the participants were assured that data processing in the study would comply with the applicable standards of data security, confidentiality, and ethics. The study was approved by the University of Almería Bioethics
Committee, Spain (Ref: UALBIO2017/011). The questionnaire was administered in 2017 on a Web platform that enabled the participants to fill it in online. A series of control questions were inserted to control for random or incongruent answers, which were then eliminated from the study.

\section{Data Analysis}

The study was quantitative, observational, and cross-sectional. First, Pearson's correlation analyses were performed. A Bayesian analysis was done of the pairs in which significance was from 0.01 to 0.05 for a more accurate statistic in the comparison of hypotheses. This evaluates the predictive adequacy of the null hypothesis, $\mathrm{H}_{0}: \rho=0$, which stipulates that the correlation is absent, and compares it with the predictive adequacy of an alternative hypothesis $\mathrm{H}_{1}$, which stipulates that the correlation exists (Wagenmakers et al., 2016).

Mediation models were proposed based on the results found from the correlation matrices. Two mediation analyses were performed with multiple predictors, one mediator and four result variables, using JASP version 0.11.1 (JASP Team, 2019), based on the lavaan software (Rosseel, 2012). To test whether there was an indirect effect, the bias-corrected bootstrap confidence interval was applied (Biesanz et al., 2010). To examine the reliability of the instruments used for collecting data, the McDonald's Omega coefficient was estimated, following the proposal and instructions of McDonald (1999), Ventura-León and Caycho (2017). The GLB was also estimated.

\section{RESULTS}

\section{Preliminary Analyses}

The mean scores and standard deviations of each of the study variables were as follows: Positive affect $(M=2.99, S D=0.43)$, negative affect $(M=2.09, S D=0.39)$, extraversion $(M=3.50, S D$ $=0.80)$, agreeableness $(M=4.01, S D=0.58)$, conscientiousness $(M=3.87, S D=0.67)$, neuroticism $(M=2.67, S D=0.81)$, openness to experience $(M=3.51, S D=0.74)$, problem solving $(M=13.59, S D=3.96)$, self-criticism $(M=6.05, S D=4.16)$, emotion expression $(M=10.31, S D=3.83)$, wishful thinking $(M=10.67, S D=4.73)$, social support $(M=13.27, S D=$ $4.40)$, cognitive restructuring $(M=11.75, S D=3.91)$, problem avoidance $(M=6.98, S D=3.74)$, and social withdrawal $(M=$ $4.76, S D=3.49$ ).

Table 1 shows the pairwise correlation matrix for the affect and personality factors. Positive affect correlated positively with extraversion, agreeableness, conscientiousness, and openness to experience and had a negative relationship with neuroticism. Negative affect correlated positively with neuroticism and negatively with the rest of personality factors.

The Bayes factor for negative affect-extroversion was $\left(\mathrm{BF}_{-0}=\right.$ $1.802,95 \% \mathrm{CI}=-0.126,-0.019)$, which indicates that the data are 1.8 times more likely under the alternative hypothesis that expresses the existence of a negative correlation than under the null hypothesis. In line with Jeffreys (1961), a Bayes factor from 1 to 3 is considered weak or inconclusive evidence, a Bayes factor from 3 to 10 is considered moderate evidence, and a Bayes factor above 10 is considered strong evidence. 
TABLE 1 | Affect and personality - Pearson's pairwise correlations.

\begin{tabular}{|c|c|c|c|c|c|}
\hline Affect & Personality & Pearson's $r$ & $p$ & Below 95\% Cl & Above $95 \% \mathrm{Cl}$ \\
\hline \multirow[t]{5}{*}{ Positive } & Extraversion & 0.126 & $<0.001$ & 0.071 & 0.179 \\
\hline & Agreeableness & 0.106 & $<0.001$ & 0.051 & 0.160 \\
\hline & Conscientiousness & 0.202 & $<0.001$ & 0.149 & 0.255 \\
\hline & Neuroticism & -0.146 & $<0.001$ & -0.200 & -0.092 \\
\hline & Openness & 0.177 & $<0.001$ & 0.123 & 0.230 \\
\hline & Conscientiousness & -0.143 & $<0.001$ & -0.197 & -0.089 \\
\hline & Neuroticism & 0.256 & $<0.001$ & 0.203 & 0.306 \\
\hline & Openness & -0.060 & 0.032 & -0.115 & -0.005 \\
\hline
\end{tabular}

In the negative affect-openness to experience pair, the Bayes factor was $\left(\mathrm{BF}_{-0}=0.684,95 \% \mathrm{CI}=-0.115,-0.011\right)$, which shows that the data are 1.46 times more likely under the null hypothesis than under the alternative hypothesis.

Table 2 presents the pairwise correlations between the affects and coping strategies. In the first place, problem-solving coping strategies and seeking social support were positively related with positive affect, while the other strategies based on selfcriticism, wishful thinking, and social withdrawal showed positive correlations with negative affect.

Furthermore, other coping strategies were identified that were positively related with both affects: emotion expression, cognitive restructuring, and problem avoidance.

Regarding the pairwise correlations between personality factors and coping strategies, coping strategies based on problemsolving correlated positively with extraversion, agreeableness, conscientiousness, and openness to experience, while the correlation with neuroticism was negative.

The self-criticism strategy was positively related to neuroticism and negatively to the rest of the personality factors.

Emotion expression showed positive correlations with all the personality factors except neuroticism with which it was not correlated.

Coping directed at wishful thinking correlated positively with neuroticism and, to a lesser extent, with agreeableness. Seeking social support correlated positively with all the personality factors and negatively with neuroticism, as did the cognitive restructuring strategy.

In addition, problem-avoidance coping was negatively related with agreeableness and conscientiousness.

Finally, social withdrawal was a coping strategy associated positively with neuroticism and negatively with the four remaining personality factors.

\section{Mediation Models}

Two mediation models were proposed as follows (Figure 1):

Model 1, which proposes positive affect as a mediator in the relationship between the personality dimensions and positive coping strategies (considered as such based on the preliminary results of positive relationships of affect and the personality dimensions that could be beneficial, in this case, for professional practice).

Model 2 hypothesized the existence of a mediating effect of negative affect in the relationship established between the personality factors and the use of negative coping strategies.

As observed in Table 3, the extraversion and agreeableness factors showed direct positive effects on the "positive" coping strategies (problem-solving, cognitive restructuring, social support, and emotion expression). The conscientiousness factor had a direct positive effect on the problem-solving strategy and, to a lesser extent, on cognitive restructuring. On these two strategies, although negatively, a direct effect of neuroticism was observed, whereas the openness to experience factor exerted a direct positive effect on problem-solving and social support.

As indirect effects, positive affect mediated in the relationship of extraversion with problem-solving, social support, and emotion expression. Positive affect also mediated in the relationships of the agreeableness factor with problem-solving, cognitive restructuring, and emotion expression.

Furthermore, positive affect was a mediator in the relationship of conscientiousness with the problem-solving, cognitive restructuring, and social support coping strategies. Finally, positive affect was observed to mediate in the relationships between openness to experience and cognitive restructuring, social support, and emotion expression.

Finally, the proportion of variance explained for each of the endogenous variables in Mediation Model 1 is the following: $R^{2}=$ 0.237 for problem-solving, $R^{2}=0.116$ for cognitive restructuring, $R^{2}=0.157$ for social support, $R^{2}=0.096$ for emotion expression, and $R^{2}=0.070$ for the positive affect mediator.

Table 4 shows that the extraversion factor exerted a direct negative effect on the self-criticism and social withdrawal coping strategies. The agreeableness factor had a direct positive effect on wishful thinking and a negative effect on social withdrawal. The conscientiousness factor had a direct negative effect on the problem avoidance, social withdrawal, and self-criticism strategies, while the neuroticism factor exerted a direct positive effect on wishful thinking, social withdrawal, and self-criticism strategies.

As to the indirect effects, negative affect was observed to exert a mediating role in the relationship of extraversion with social 
TABLE 2 | Affect, personality, and coping strategies - Pearson's pairwise correlations.

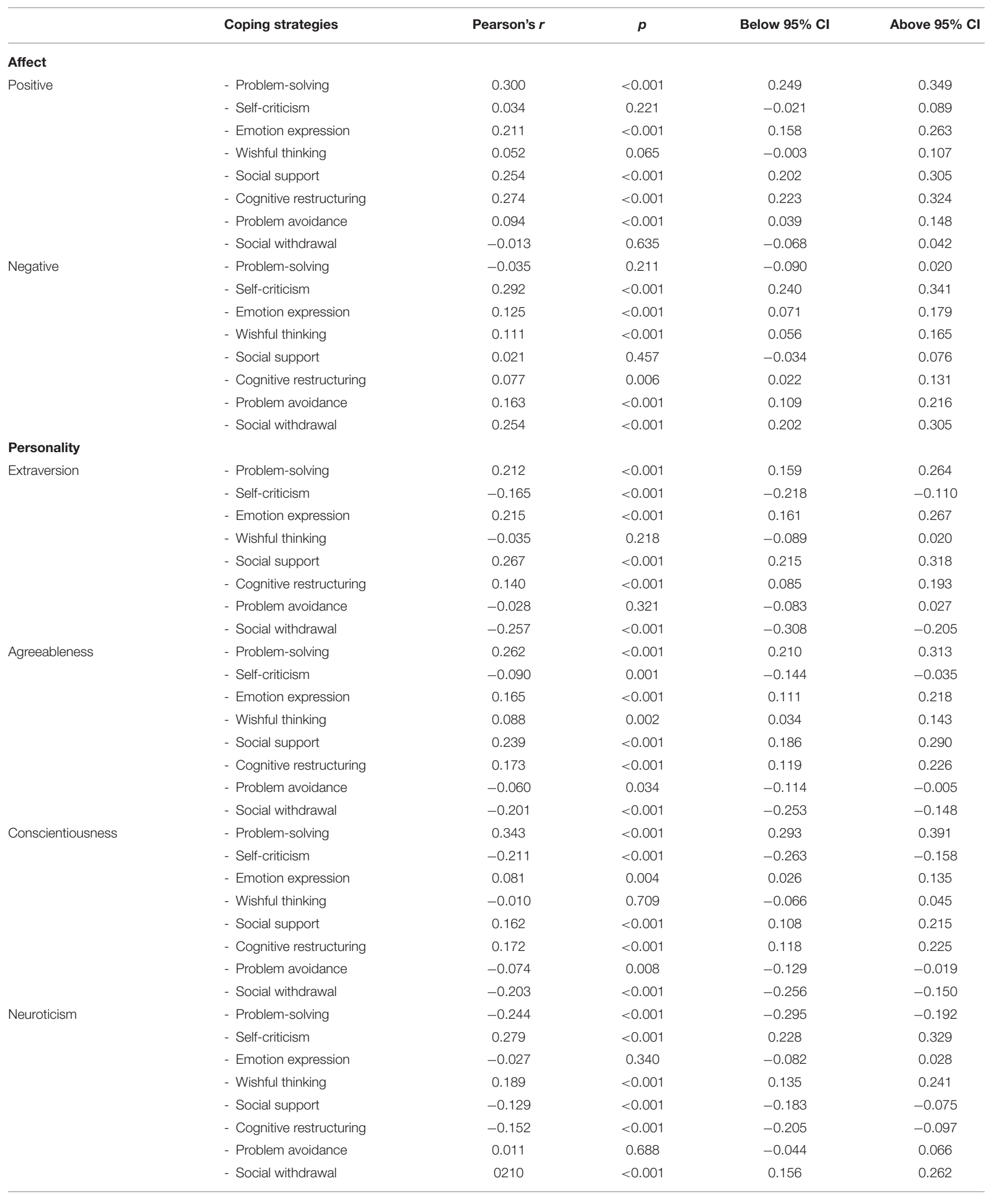


TABLE 2 | Continued

\begin{tabular}{|c|c|c|c|c|c|}
\hline & Coping strategies & Pearson's $r$ & $p$ & Below $95 \% \mathrm{Cl}$ & Above $95 \% \mathrm{Cl}$ \\
\hline \multirow[t]{6}{*}{ Openness to experience } & - Problem-solving & 0.249 & $<0.001$ & 0.197 & 0.300 \\
\hline & - Self-criticism & -0.114 & $<0.001$ & -0.168 & -0.059 \\
\hline & - Emotion expression & 0.101 & $<0.001$ & 0.047 & 0.156 \\
\hline & - Wishful thinking & 0.004 & 0.881 & -0.051 & 0.059 \\
\hline & - Social support & 0.168 & $<0.001$ & 0.114 & 0.221 \\
\hline & - Social withdrawal & -0.100 & $<0.001$ & -0.154 & -0.045 \\
\hline
\end{tabular}

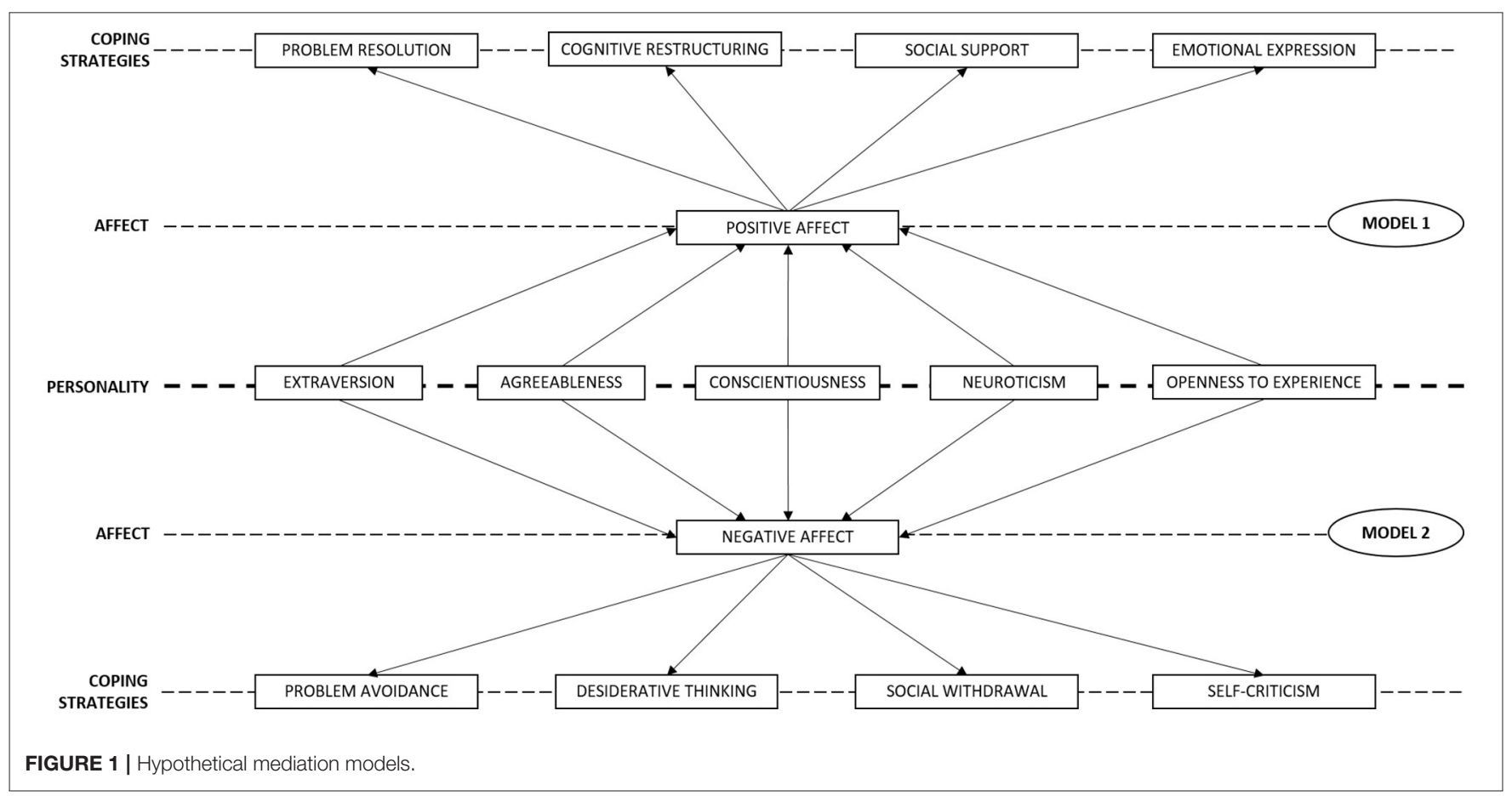

withdrawal and self-criticism. Negative affect further mediated in the relationship of the conscientiousness factor with the problem avoidance and self-criticism coping strategies. For neuroticism, negative affect intervened as a mediator in its relationships with the problem avoidance and wishful thinking strategies. Finally, the mediator effect of negative affect was present in the relationships between the openness and problem avoidance, wishful thinking, and social withdrawal coping strategies.

Finally, the proportion of variance explained for each of the endogenous variables in Mediation Model 1 was the following: $R^{2}$ $=0.033$ for problem avoidance, $R^{2}=0.056$ for wishful thinking, $R^{2}=0.156$ for social withdrawal, $R^{2}=0.155$ for self-criticism, and $R^{2}=0.075$ for the negative affect mediator.

\section{DISCUSSION}

The objective of this study was to analyze the relationship of the coping strategies with affect and individual personality. In the first place, and in agreement with the literature
(Hall et al., 2016; Hengartner et al., 2017), positive relationships were found between positive affect and all the Big Five Model traits except neuroticism, with which it shows a negative association, while the relationship of negative affect with the personality factors was the contrary.

In addition, concerning the relationships between affect and the coping strategies, a positive association was found between positive affect and adequate problem management or emotion, while negative affect showed a positive relationship mostly with strategies considered inadequate. Thus, while positive affect was especially related to active effort for compensating a stressful situation, negative affect would be linked to maladaptive coping with stress, showing a passive attitude by avoiding the problem. Previous studies have shown the negative role in harmful interpretation of the stressful situation, which could lead to overestimation of risk, and therefore avoiding confrontation with it or avoiding the distress associated with it (Dunkley et al., 2017). On the contrary, a positive affective state in stressful events means that one is active, lively, and alert, and so feels more confident of 
TABLE 3 | Direct and indirect effects (Model 1).

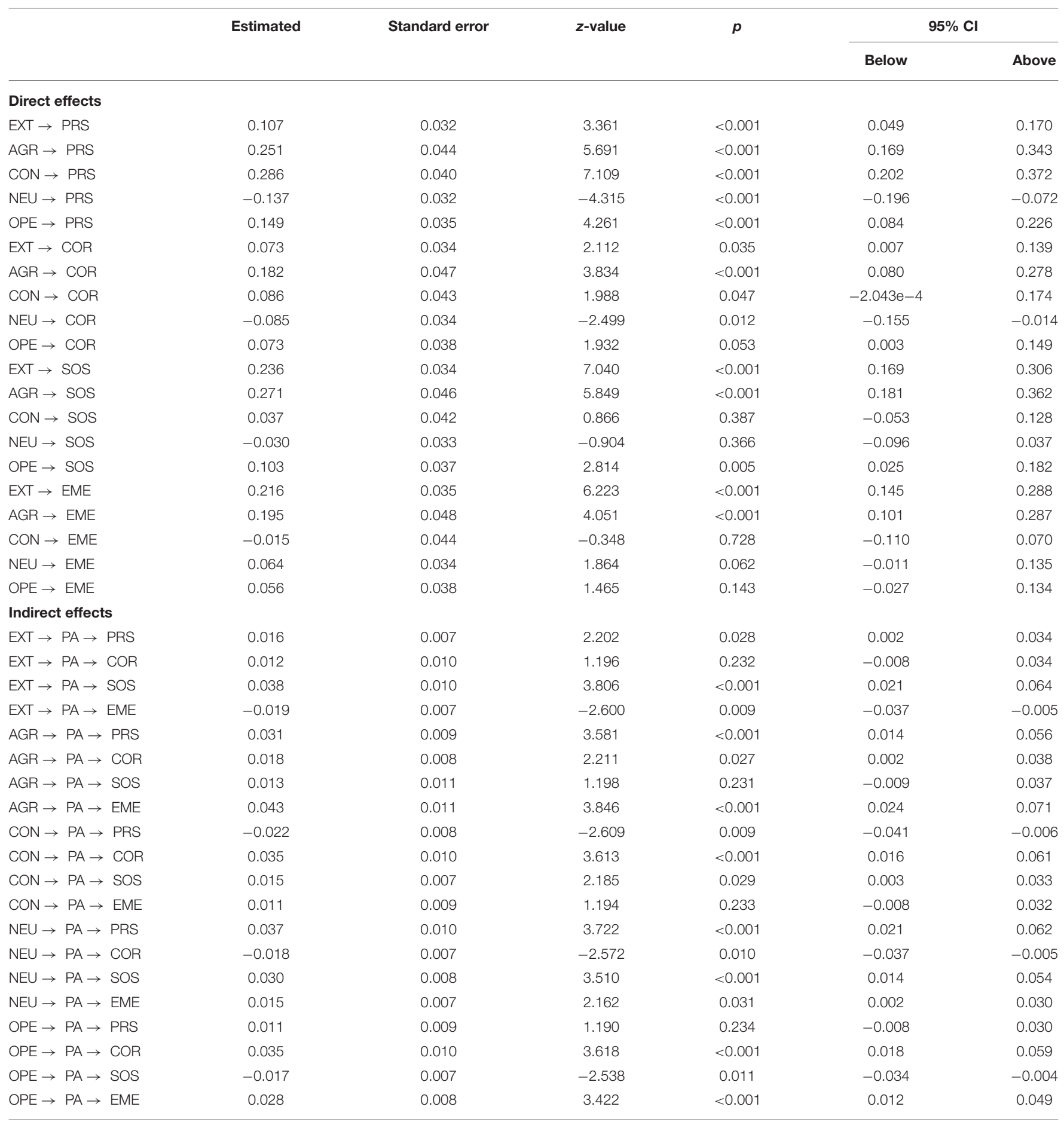

EXT, extraversion; AGR, agreeableness; CON, conscientiousness; NEU, neuroticism; OPE, openness to experience; PRS, problem-solving; COR, cognitive restructuring; SOS, social support; EME, emotion expression; PA, positive affect.

Delta method standard error, bias-corrected percentile bootstrap confidence interval.

the ability of an individual to deal with the problem successfully, personality traits considered more adaptive (extraversion, mainly by choosing active strategies (Cano-García et al., 2007). agreeableness, conscientiousness, and openness to experience)

The relationship between the Big Five factors and coping showed positive relationships with the more well-adjusted strategies was also confirmed, finding that the most prevalent coping strategies and negative relationships with the 
TABLE 4 | Direct and indirect effects (Model 2).

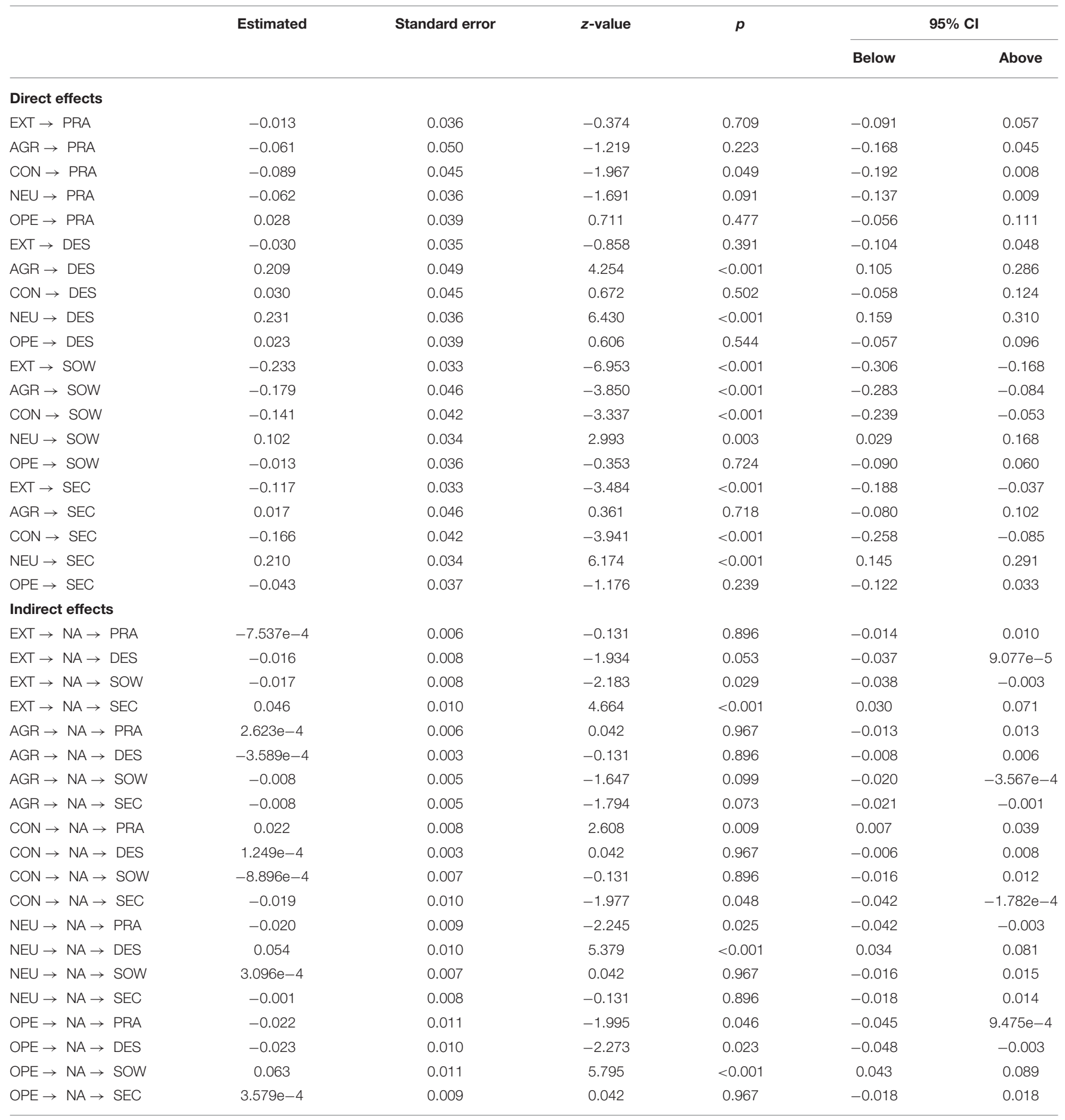

EXT, extraversion; AGR, agreeableness; CON, conscientiousness; NEU, neuroticism; OPE, openness to experience; PRA, problem avoidance; DES, desiderative thinking; SOW, social withdrawal; SEC, self-criticism; NA, negative affect.

Delta method standard error, bias-corrected percentile bootstrap confidence interval.

negative coping strategies. Meanwhile, the neuroticism factor showed the opposite relationship with coping strategies, such that it associated positively with strategies typical of a negative approach and negatively with more adequate ways of managing the stressful event (Cano-García et al., 2007).

Then, the two mediation models were estimated. In the first model, it was observed that positive affect acted as 
a mediator in the relationship between neuroticism and all the positive strategies. Although this result may at first seem surprising, according to previous literature, this trait is especially linked to affect and regulation strategies (Pavani et al., 2017). In particular, individuals with high levels of neuroticism may select adaptive coping strategies when the affective burden of the situation is positive (Augustine and Larsen, 2011). Thus, even though emotional instability typical of the neuroticism factor usually leads to negative evaluation of the situation, and therefore a greater tendency to select negative solution strategies (Fornés-Vives et al., 2019), a person with high neuroticism may prefer strategies that promote adequate management in the presence of an enthusiastic, alive affective state. Similarly, those with personality traits considered positive select proactive problem-solving strategies and relieve the emotional distress through positive affect which means dealing with the situation actively and optimistically (Korotkov, 2008; Straud et al., 2015; Pavani et al., 2017).

The second model shows how negative affect mediated the effect of extraversion on inadequate emotion-focused management, wishful thinking, conscientiousness, problem avoidance, and self-criticism strategies; the neuroticism factor and inadequate problem-focusing management strategies; and the openness to experience trait and problem avoidance strategies, social withdrawal, and wishful thinking. Thus, when the affective state is marked by negative feelings, such as fear or guilt, coping strategies considered maladaptive may end up being employed, regardless of personality traits. Therefore, acquisition and development of effective coping strategies to solve the frequent stressful situations in the healthcare job context (Huang et al., 2018) goes through training in adequate problem management strategies as well as intervention on the affect generated by such events. This means undertaking the regulation dynamics between employee coping, affect, and personality together (De la Barrera et al., 2019).

It is important to state some limitations. In the first place, the characteristics of the stressful situation were not taken into account. The CSI asks the subject in the instructions to think of a situation experienced in the last month and evaluate the coping strategies used for it. As the situation remembered may have an affective load and different intensity in each case, and therefore be related to the type of coping selected, in future studies, the nature of the stressful event selected should be taken into consideration. We should also mention the short length of the instrument used to assess personality. Even though it is so short, it can be beneficial because it is easy to apply, although it may also reduce the measurement efficacy. Variables such as age, years of experience, or the department where they were

\section{REFERENCES}

Anisman, H., Hayley, S., and Kusnecov, A. (2018). The Immune System and Mental Health. Amsterdam: Elsevier.

Augustine, A. A., and Larsen, R. J. (2011). Affect regulation and temporal discounting: interactions between primed, state, and trait affect. Emotion 11, 403-412. doi: 10.1037/a0021777 working were not taken into account either. In future studies, these factors should be controlled for, given their connection with coping strategies.

\section{CONCLUSIONS}

Since the exposure of nurses to stress is so high, inadequate management can cause more vulnerability to the development of physical and psychological affects, while adaptive coping promotes wellbeing and effective solution. This study showed that personality can be closely linked to the way worker stress is handled. However, the affective state mediates in this relationship, such that when negative affect is experienced, stressful events are managed less adaptively, and when positive affect is present, it acts as a mediator between personality factors and positive coping strategies.

Therefore, this study shows the need to continue inquiry into factors involved in effective coping with stressful situations in the nursing work environment and variables related with their appearance. Their in-depth knowledge would make it possible to develop actions teaching adequate problem-solving strategies and training in the ability to assign a different emotional value to complicated situations.

\section{DATA AVAILABILITY STATEMENT}

The original contributions presented in the study are included in the article, further inquiries can be directed to the corresponding author.

\section{ETHICS STATEMENT}

The studies involving human participants were reviewed and approved by the Bioethics Committee of the University of Almería (Ref: UALBIO2017/011). The patients/participants provided their written informed consent to participate in this study.

\section{AUTHOR CONTRIBUTIONS}

MCP-F, MMMJ, ÁMM, ABBM, and MMSM contributed to the conception and design of the review. JJGL and ABBM applied the search strategy. MCP-F, MMMJ, and ÁMM wrote this manuscript. MCP-F and JJGL edited this manuscript. All authors applied the selection criteria, completed the assessment of the risk of bias, analyzed the data and interpreted data, and read and agreed to the published version of the manuscript.
Bamonti, P., Conti, E., Cavanagh, C., Gerolimatos, L., Gregg, J., Goulet, C., et al. (2019). Coping, cognitive emotion regulation, and burnout in longterm care nursing staff: a preliminary study. J. Appl. Gerontol. 38, 92-111. doi: $10.1177 / 0733464817716970$

Barr, P. (2018). Personality traits, state positive and negative affect, and professional quality of life in neonatal nurses. J. Obstet. Gynecol. Neonatal. Nurs. 47, 771-782. doi: 10.1016/j.jogn.2018.08.003 
Biesanz, J. C., Falk, C. F., and Savalei, V. (2010). Assessing mediational models: testing and interval estimation for indirect effects. Multivar. Behav. Res. 45, 661-701. doi: 10.1080/00273171.2010.498292

Cano-García, F. J., Rodríguez-Franco, L., and García-Martínez, J. (2007). Adaptación Española del Inventario de Estrategias de Afrontamiento [Spanish Adaptation of the Inventory of Coping Strategies]. Actas. Esp. Psiquiatr. 35, 29-39.

Davis, K. L., and Panksepp, J. (2011). The brain's emotional foundations of human personality and the Affective Neuroscience Personality Scales. Neurosci. Biobehav. Rev. 35, 1946-1958. doi: 10.1016/j.neubiorev.2011.04.004

De la Barrera, U., Villanueva, L., and Prado-Gascó, V. (2019). Emotional and personality predictor that influence the appearance of somatic complaints in children and adults. Psicothema 31, 407-413. doi: 10.7334/psicothema2019.69

Dunkley, D. M., Lewkowski, M., Lee, I. A., Preacher, K. J., Zuroff, D. C., Berg, J. L., et al. (2017). Daily stress, coping, and negative and positive affect in depression: complex trigger and maintenance patterns. Behav. Ther. 48, 349-365. doi: 10.1016/j.beth.2016.06.001

Dykstra, J. G., Sendelbach, D., and Steege, L. M. (2016). Fatigue in float nurses: patient, nurse, task, and environmental factors across unit work systems. Proc. Hum. Factors. Ergon. Soc. Annu. Meet. 60, 5-17. doi: $10.1177 / 1541931213601142$

Folkman, S. (2013). "Stress: appraisal and coping," in Encyclopedia of Behavioral Medicine, eds M. D. Gellman and J. R. Turner (New York, NY: Springer), 1913-1915.

Fornés-Vives, J., García-Banda, G., Frías-Navarro, D., and Pascual-Soler, M. (2019). Longitudinal study predicting burnout in Spanish nurses: the role of Neuroticismo and emotional coping. Pers. Individ. Differ. 138, 286-291. doi: $10.1016 /$ j.paid.2018.10.014

Forozeiya, D., Vanderspank-Wright, B., Fothergill, F., Moreau, D., and Wrighjt, D. K. (2019). Coping with moral distress-the experiences of intensive care nurses: an interpretive descriptive study. Intensive. Crit. Care Nurs. 53, 23-29. doi: 10.1016/j.iccn.2019.03.002

Hall, J. A., Gunnery, S. D., Letzring, T. D., Carney, D. R., and Colvin, C. R. (2016). Accuracy of judging affect and accuracy of judging personality: how and when are they related? J. Pers. 85, 583-592. doi: 10.1111/jopy.12262

Hengartner, M. P., Graf, M., and Schreiber, M. (2017). Traits across the personality hierarchy differentially relate to positive and negative affect: evidence for the predictive validity of empirically derived meta-traits. Pers. Ment. Health. 11, 132-143. doi: 10.1002/pmh.1366

Huang, C. C., Lee, F. Y., Yang, L. Y., Yang, Y., Chen, C. H., Liang, J. F., et al. (2018). Mixed simulation course increases participants' positive stress coping abilities. J. Chin. Med. Assoc. 81, 58-63. doi: 10.1016/j.jcma.2017.07.013

JASP Team (2019). JASP (Version 0.11.1) [Computer software].

Jeffreys, H. (1961). Theory of Probability, 3rd Edn. Oxford: Oxford University Press.

Jia, H., Uphold, C. R., Wu, S., Reid, K.,Findley, K., and Ducan, P. W. (2004). Health-related quality of life among men with hiv infection: effects of Apoyo social, coping, and depression. AIDS Patient Care STDs 18, 594-603. doi: 10.1089/apc.2004.18.594

Joiner, T., Sandin, B., Chorot, P., Lostao, L., and Marquina, G. (1997). Development and factor analytic validation of the SPANAS among women in spain: (more) cross-cultural convergence in the structure of mood. J. Pers. Assess. 68, 600-615. doi: 10.1207/s15327752jpa6803_8

Kellog, M. B., Knight, M., Dowling, J., and Crawford, S. L. (2018). Secondary traumatic stress in pediatric nurses. J. Pediatr. Nurs. 43, 97-103. doi: 10.1016/j.pedn.2018.08.016

Korotkov, D. (2008). Does personality moderate the relationship between stress and health behavior? expanding the nomological network of the five-factor model. J. Res. Pers. 42, 1418-1426. doi: 10.1016/j.jrp.2008.06.003

Mark, G., and Smith, A. P. (2012). Occupational stress, job characteristics, coping, and the mental health of nurses. Br. J. Health Psychol. 17, 505-521. doi: 10.1111/j.2044-8287.2011.02051.x

McDonald, R. P. (1999). Test Theory: A Unified Approach. Mahwah, NJ: Lawrence Erlbaum Associates.

Molero, M. M., Pérez-Fuentes, M. C., Gázquez, J. J., and Barragán, A. B. (2018b). Burnout in health professionals according to their self-esteem, social support and empathy profile. Front. Psychol. 9:424. doi: 10.3389/fpsyg.2018. 00424
Molero, M. M., Pérez-Fuentes, M. C., Gázquez, J. J., Simón, M. M., and Martos, Á. (2018a). Burnout risk and protection factors in certified nursing aides. Int. J. Environ. Res. Public. Health 15:1116. doi: 10.3390/ijerph15061116

Molero, M. M., Pérez-Fuentes, M. C., Oropesa, N. F., Simón, M., and Gázquez, J. J. (2019). Self-Efficacy and Emotional Intelligence as Predictors of Perceived Stress in Nursing Professionals. Medicina 55:237. doi: 10.3390/medicina55060237

Morales, F. M. (2020). Coping strategies, empathy, and prosocial tendencies in university students. Eur. J. Educ. Psychol. 13, 187-200. doi: 10.30552/ejep.v13i2.360

Pavani, J. B., Le Vigouroux, S., Kop, J. L., Congard, A., and Dauvier, B. (2017). A network approach to affect regulation dynamics and personality trait-induced variations: extraversion and neuroticismo moderate reciprocal influences between affect and affect regulation strategies. Eur. J. Pers. 31, 329-346. doi: 10.1002/per.2109

Pérez-Fuentes, M. C., Molero, M. M., Gázquez, J. J., and Simón, M. M. (2019a). Analysis of burnout predictors in nursing: risk and protective psychological factors. Eur. J. Psychol. Appl. Leg. Context 11,33-40. doi: 10.5093/ejpalc2018a13

Pérez-Fuentes, M. C., Molero, M. M., Martos, Á., and Gázquez, J. J. (2019b). Burnout and engagement: personality profiles in nursing professionals. J. Clin. Sleep. Med. 8:286. doi: 10.3390/jcm8030286

Rammstedt, B., and John, O. P. (2007). Measuring personality in one minute or less: a 10-item short version of the Big Five Inventory in English and German. J. Res. Pers. 41, 203-212. doi: 10.1016/j.jrp.2006.02.001

Rammstedt, B., Kemper, C. J., Klein, M. C., Beierlein, C., and Kovaleva, A. (2014). Big Five Inventory (BFI-10). Zusammenstellung sozialwissenschaftlicher Items und Skalen (ZIS). doi: 10.6102/zis76

Rosseel, Y. (2012). Lavaan: an R package for structural equation modeling and more. Version 0.5-12 (BETA). J. Stat. Softw. 48, 1-36. doi: 10.18637/jss.v048.i02

Sahler, O. J. Z., and Carr, J. E. (2009). "Coping strategies," in Developmental-Behavioral Pediatrics, eds W. B. Carey, A. C. Crocker, W. L. Coleman, E. R. Elias, and H. M. Feldman (https://www.google.com/search?sxsrf=ALeKk002KtD3F_L6 -ab_8x8MIVrA3KaDqg:1628149466692\&q=Amsterdam\&stick= H4sIAAAAAAAAAOPgE-LUz9U3MDJLSYpXYgcxs40LtLSyk63084vSE _MyqxJLMvPzUDhWGamJKYWliUUlqUXFilg5HXOLgayUxNwdrIwA9iXLV lEAAAA\&sa=X\&ved=2ahUKEwi3w-m0sZnyAhUUgOYKHd-9CBcQmxMo ATAyegQIMxADAmsterdam:Elsevier), 491-496.

Schreuder, J. A. H., Roelen, C. A. M., Groothoff, J. W., van der Klink, J. J. L., Mageroy, N., Pallesen, S., et al. (2012). Coping styles relate to health and work environment of Norwegian and Dutch hospital nurses: a comparative study. Nurs. Outlook 60, 37-43. doi: 10.1016/j.outlook.2011.05.005

Schürmann, J., and Magraf, J. (2018). Age of anxiety and depression revisited: a meta-analysis of two European community samples (1964-2015). Int. J. Clin. Health Psychol. 18, 102-112. doi: 10.1016/j.ijchp.2018.02.002

Serrano-Fernández, M. J., Boada-Grau, B. G., Gil-Ripoll, C., and Vigil-Colet, A. (2019). A predictive study of antecedent variables of Passion towards Work. Ann. Psychol. 35, 490-495. doi: 10.6018/analesps.35.3.331091

Straud, C., McNaughton-Cassill, M., and Fuhrman, R. (2015). The role of the five factor model of personality with proactive coping and preventative coping among college students. Pers. Individ. Differ. 83, 60-64. doi: $10.1016 /$ j.paid.2015.03.055

Teismann, T., Brailovskaia, J., and Margraf, J. (2019). Positive mental health, positive affect, and suicide ideation. Int. J. Clin. Health Psychol. 19, 165-169. doi: 10.1016/j.ijchp.2019.02.003

Teismann, T., Forkmann, T., Brailovskaia, J., Siegmann, P., Glaesmer, H., and Margraf, J. (2018). Positive mental health moderates the association between depression and suicide ideation: a longitudinal study. Int. J. Clin. Health Psychol. 18, 1-7. doi: 10.1016/j.ijchp.2017.08.001

Tirado, G., Llorente-Alonso, M., and Topa, G. (2019). Effort-reward imbalance and subjective health complaints: exploratory study among physicians in Spain. Eur. J. Investig. Health Psychol. Educ. 9, 59-70. doi: 10.30552/ejihpe.v9 i2.320

Veiga, G., Dias, A., Lamy, E., Guiose, M., Pereira, C., and Marmeleira, J. (2019). The effects of a relaxation intervention on nurses' psychological and physiological stress indicators: a pilot study. Complement. Ther. Clin. Pract. 35, 265-271. doi: 10.1016/j.ctcp.2019.03.008 
Ventura-León, J. L., and Caycho, T. (2017). El coeficiente Omega: un método alternativo para la estimación de la confiabilidad [The Omega coefficient: an alternative method for estimating reliability]. Rev. Latinoam. Cienc. Soc. Niñez Juv. 15, 625-627.

Voskou, P., Bougea, A., Economou, M., Douzenis, A., and Ginieri-Coccossis, M. (2020). Relationship of quality of life, psychopathologic symptoms and ways of coping in Greek nursing staff. Enferm. Clínica 30, 23-30. doi: 10.1016/j.enfcli.2018.10.006

Wagenmakers, E. J., Morey, R. D., and Lee, M. D. (2016). Bayesian benefits for the pragmatic researcher. Curr. Dir. Psychol. 25, 169-176. doi: 10.1177/0963721416643289

Watson, D., Clark, L. A., and Tellegen, A. (1988). Development and validation of brief measures of positive and negative affect: the PANAS scales. J. Pers. Soc. Psychol. 54, 1063-1070. doi: 10.1037/0022-3514.54. 6.1063

Wechler, S. M., Benson, N., de Lara, W., Bachert, C. M. A., and Gums, E. (2018). Adult temperament styles: a network analysis of their relationships with the Big Five Personality Model. Eur. J. Educ. Psychol. 11, 61-75. doi: 10.30552/ejep.v11i1.186

Wiebe, D. J., Song, A., and Ramírez, M. D. (2018). “Chapter 12-what mechanisms explain the links between personality and health?" in Personality and Disease: Scientific Proof Vs. Wishful Thinking, ed C. Johansen (Amsterdam: Elsevier), 223-245.

Wijn, A. N., and van der Doef, M. P. (2020). Patient-related stressful situations and stress-related outcomes in emergency nurses: a cross-sectional study on the role of work factors and recovery during leisure time: stressful situations in emergency nurses. Int. J. Nurs. Stud. 107:103579. doi: 10.1016/j.ijnurstu.2020.103579

Yu, F., Raphael, D., Mackay, L., Smith, M., and King, A. (2019). Personal and work-related factors associated with nurse resilience: a systematic review. Int. J. Nurs. Stud. 93, 129-140. doi: 10.1016/j.ijnurstu.2019.02. 014

Conflict of Interest: The authors declare that the research was conducted in the absence of any commercial or financial relationships that could be construed as a potential conflict of interest.

Publisher's Note: All claims expressed in this article are solely those of the authors and do not necessarily represent those of their affiliated organizations, or those of the publisher, the editors and the reviewers. Any product that may be evaluated in this article, or claim that may be made by its manufacturer, is not guaranteed or endorsed by the publisher.

Copyright (c) 2021 Martos Martínez, Molero Jurado, Pérez-Fuentes, Barragán Martín, Simón Márquez and Gázquez Linares. This is an open-access article distributed under the terms of the Creative Commons Attribution License (CC BY). The use, distribution or reproduction in other forums is permitted, provided the original author(s) and the copyright owner(s) are credited and that the original publication in this journal is cited, in accordance with accepted academic practice. No use, distribution or reproduction is permitted which does not comply with these terms. 